\title{
Quantifying the Impact of Urban Microclimate in Detailed Urban Building Energy Simulations
}

\author{
Georgios-Evrystheas Kyriakodis ${ }^{1,2}$, Emmanuel Bozonnet ${ }^{1}$, Peter Riederer $^{2}$ \\ ${ }^{1}$ University of La Rochelle, La Rochelle, France \\ ${ }^{2}$ CSTB, Sophia-Antipolis, France
}

\begin{abstract}
The study focuses on the development and illustration of the interactions between urban microclimate and district scale building simulation through a micro co-simulation approach. A zonal microclimatic model developed to serve the needs of the district scale is coupled with an Urban Building Energy Model aiming a twofold objective: enhancement of the boundary conditions and adaptation of the built environment to heat island mitigation measures. The proposed coupling strategy is analysed and presented through a case study of a street canyon. The initial outcomes exhibit deviations between the standalone and the coupled models.
\end{abstract}

\section{Introduction}

The built environment constitutes the largest artificial key contributor, modifying the thermal balance of the urban microclimate and constituting the dominant energy consumer with $48 \%$ for France and $40 \%$ for Europe ('Eurostat', 2017). At the same time, the Urban Heat Island (UHI) effect, combined with the global warming, causes various deterioration factors: mainly, aggravating the outdoor thermal comfort conditions and intensifying both the energy consumption and peaks for cooling (Santamouris et al., 2015), especially for cities within moderate climate zones (30-60 latitude).

To this end, the last years several approaches and simulations methods have been emerged with the aim of studying the building energy demand with respect to the microclimate. They can be classified to various spatial or temporal scales, depending on the studied objectives, the time step calculation and the simulation time efficiency (Frayssinet, L. et al. 2018). Following this classification, two main methods dominate building energy simulation (BES), the top-down (from urban to building) and bottomup (from building and system up to the urban scale) approaches (Bozonnet et al., 2015). Similarly, studies of urban microclimate, follow the same trend, the downscaling (from global/region to city) and the upscaling (from urban canyon to city) approaches respectively.

More in detail, BES is developing to serve the NZEB design and to represent the thermal processes at building scale. These models, also used in building regulations, target to evaluate / predict the energy use and buildings' environmental footprint. Uncertainties arise due to isolation from the urban context and the use of reference weather data (rural) far from bias due to anthropogenic sources and heterogeneous urban morphology. In addition, the ejected thermal fluxes of the energy systems in which they operate are not taken into account, as their spatial limitation cannot assess this feedback. Consequently, they are missing the local but significant interactions between them and the urban environment ( $\mathrm{J}$. Allegrini et al., 2015).

On the other hand, the mesoscale atmospheric models initially designed with the objective to serve both atmospheric research and operational forecasting needs. Therefore, they operate in a huge range of spatial scale $(25 \mathrm{~km}$ to $1 \mathrm{~km})$. This variety of spatial resolution and the application of the downscaling method, enables them to integrate the urban parametrizations (1 km to $100 \mathrm{~m})$ and launch city-urban scale simulations with the aim of firstly assess the air pollution and secondly the UHI effect (de Munck et al., 2013). Recently, also building energy consumption is studied with such type of models (Martilli, 2007; Masson, 2000; Kusaka et al., 2001; Grimmond et al., 2010). Nevertheless, their approach to represent the built environment as cells of coverage ratios (of buildings, vegetation, open spaces and built infrastructures) prevent them from addressing the detailed urban morphology (surfaces \& obstacles) and their respective thermal fluxes properly.

Furthermore, a significant effort of representing the actual conditions in the district scale is performed with the evolution of microclimatic models, based on CFD approaches, such as ENVIMET (Bruse and Fleer, 1998). The limitations of these efforts correspond to high simulation time and simplified building parameterizations. Some efforts execute BES offlinecoupled with CFD models (Gobakis and Kolokotsa, 2017; Martin et al., 2017), but they are restrained in terms of temporal scale; from hours to day(s).

A possible way to tackle these limitations is to couple different models, each targeting different scales (Mauree et al., 2017). Such studies (Perera A.T.D. et al., 2018) have coupled an UBEM with a 1D meteorological model to enhance the meteorological input data. The work shown in this paper is triggered by this type of approach. The building (or better the building envelope) can be considered as the boundary condition (interaction interface) between the local microclimate and the building indoor environment, but also between the thermal/electrical urban network and the energy system 
inside the building. Thus, we propose the development of a coupling strategy for district energy network and microclimate simulation using a micro co-simulation approach.

The developed microclimatic model is able to represent the thermo-radiative and mass flow balances in a fine spatial resolution. In parallel, the transient energy system simulation platform is capable to consider the thermal and/or electrical grids and their respective energy storage/production on a central or local level. In parallel, both tools allow to compute the thermal processes of the buildings concurrently.

The aim of this study is twofold. At a first step, we present a direct/online coupling between the developed tools and we test the uncertainties of the BES models, emerging from the insufficient boundary conditions (microclimatic data). Additionally, we examine the impact of local (building) energy systems to the ambient environment, as well as their respective feedback, through a simplified district scale canyon settlement.

\section{Methods}

\section{Developed Simulation Platforms}

The study is based on the coupling procedure of two district scale simulation models; EnviBATE and Dimosim. The first one corresponds to a BES coupled with a radiation and a zonal model (outdoors), while the second to a BES enhanced with various modules of energy systems and networks (thermal \& electrical), control algorithms and optimization techniques. In addition, both tools have been developed in Python programming language enabling object-oriented construction.

\section{Microclimatic model}

EnviBATE's (Gros, 2014; Gros 2013) uses a reduced order model (for fast computing) for the building modelling based on the Weighting Factors method (Rousseau 1978). The model takes into account the thermal solicitations (solar Radiation $E_{\mathrm{SW}}$, outdoor surface temperatures $T_{\text {se }}$ and indoor set point $T_{\mathrm{a}}$ ) for each studied building zone and calculates the thermal responses given either free floating conditions or indoor set point temperature. The outdoor derivative flux is calculated from the given solicitations and the corresponding weighting factors $F P_{\mathrm{i}}$. The urban surfaces, acting as the interfaces between the urban canopy and the buildings, constitute the thermal surface model, which also serves the thermal balance equation.

The Radiation model (Figure 1) is based in the radiosity method using SOLENE (Groleau, Fragnaud, and Rosant 2003). The airflow model corresponds to QUIC-URB (Pardyjak and Brown 2003) dispersion model taking into account forced convection phenomena. The urban canopy model is based on the zonal model approach using the thermal balance equation for each cell volume as shown in Equation 2.

\section{Urban Building Energy model}

DIMOSIM (Riederer et al., 2015) is an integrated simulation tool for the analysis of feasibility, conception and operation of district energy systems. It consists of (a) building and thermal zone models, (b) thermal and electric network models and (c) a variety of energy system components for the various scale (sensors, emitters, hydronic distribution, production, storage and controls).

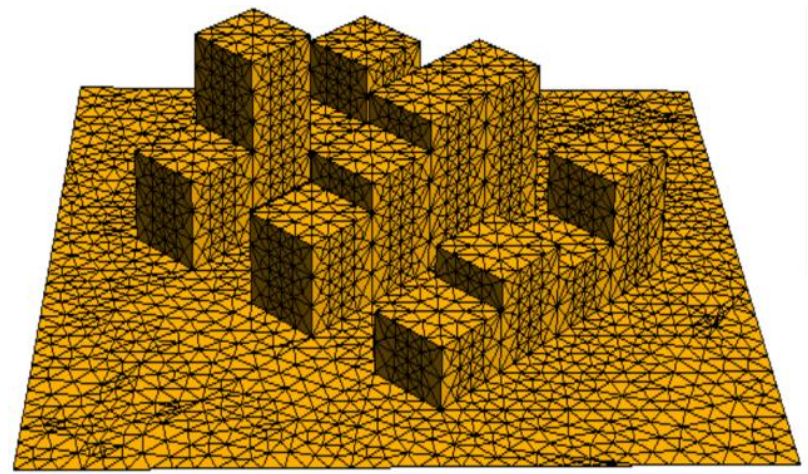

Figure 1: The triangulated mesh used for the Solar Radiation calculations.

More in detail, the main elements considered in the thermal zone model are: (a) windows, which are represented as a two-node model on the external and internal surface, (b) wall envelope model which can either be applied to each individual façade or to all facades aggregated. The user can set the number of nodes, for the discretization of the wall layers. The minimum number of nodes per wall is four, representing the external surface, a first mass layer and a second mass layer as well as the internal surface. The number of layers of each envelope can also be defined by the user. Absorbed solar short wave (SW) radiation is calculated in a specific radiation module for each façade and considering solar close and far masks. This heat flux is injected to the outer surface of the wall. On the internal surface, radiative gains from occupants, equipment and solar radiation are injected proportionally to the areas of all envelope elements (walls, ceiling, windows and floor). The roof external envelope model (c) is identical to the one of the walls except that the inclination is horizontal. The ventilation module (d) calculates heat flux to or from the zone from ventilation and/or infiltration. The flux can be positive or negative and the system can be dealt as a simple mechanical ventilation system or a ventilation system with heat recovery. Thermal bridges (e) are estimated from the number of floors, the position of the insulation and the perimeter of the zone footprint considering an average, global thermal bridge coefficient and finally (f) the internal mass module, in which all adjacent and internal walls or floors are represented and allows considering the thermal inertia of the building.

\section{Coupling Procedure}

\section{Coupling Initialization}

The coupling process required several prerequisite actions, mainly:

- Identical import layouts representing the building segments;

- Common simulation methods of the boundary conditions (ground, sky..) and solar radiation inputs; 
- The development of a coupling module enabling instantaneous data transfer, proper indexation of the coupling objects (buildings, zones, facades) and accurate setting in the matricial systems of both tools. The surface temperature constitutes the key parameter in the development of the microclimatic tool. It integrates the impact of the microclimate to building energy demand, it is thus ideal to serve the role of the main coupling state variable.

The microclimatic model is sending each simulated time step this variable together with the received incident shortwave radiation flux to the UBEM. Simultaneously, in the case of the use of split air conditioners or heat pumps/chillers, the required power to maintain the comfort standard inside the thermal zones produces a heat flux, which is linked with the outdoor environment. In our coupling scheme, this flux is injected to the outdoor environment and equals to:

$$
\Phi_{\text {cond }}^{\text {heat }}=-\varphi_{\text {emitter }} * \frac{\mathrm{COP}-1}{\mathrm{COP}}
$$

or

$$
\Phi_{\text {evap }}^{\text {cool }}=\varphi_{\text {emitter }} * \frac{\mathrm{COP}}{\mathrm{COP}-1}
$$

for the heating and cooling periods respectively. The coefficient of performance (COP) is calculated using a polynomial model for the thermodynamic process. The heat flux is taken into account from the microclimatic model solver, as shown in Figure 2 and Equation 2.

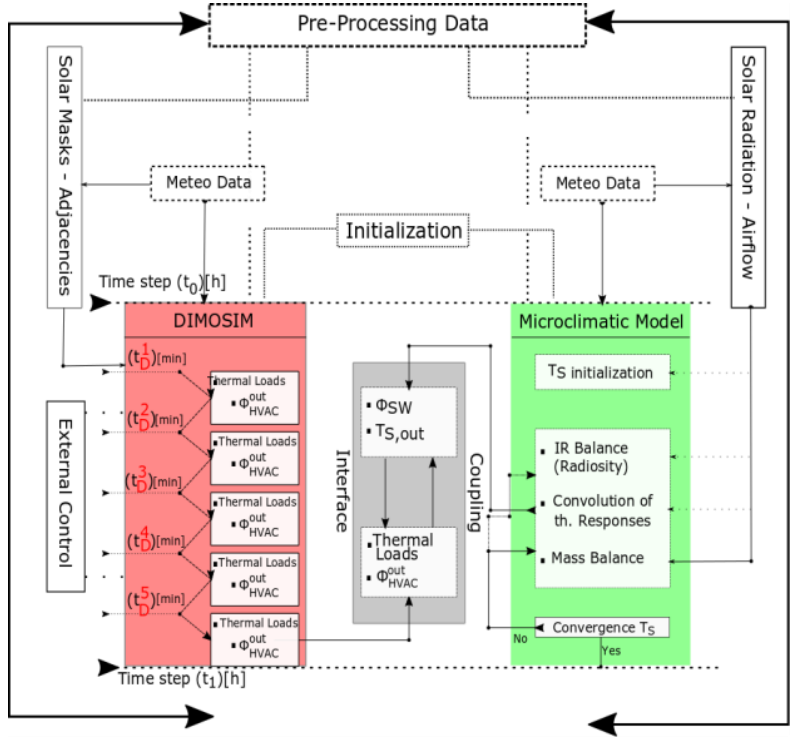

Figure 2: Schematic representation of the coupling procedure.

For the coupling setup, we chose to inject (or extract) this additional flux of the AC system(s) to the adjacent canopy cells weighted by the corresponding envelope area. In general, this option will give a good estimation of their impact to microclimate, without causing overheating problem to the canopy cells. Further advancements of the coupled tool will integrate various other options such as injected flux to one cell, a centralized generator that emits the flux at the rooftop, etc. The same approach has been adopted for the function of ventilation or infiltration. In this case, a fixed air change rate $(\mathrm{ACH})$ is set.

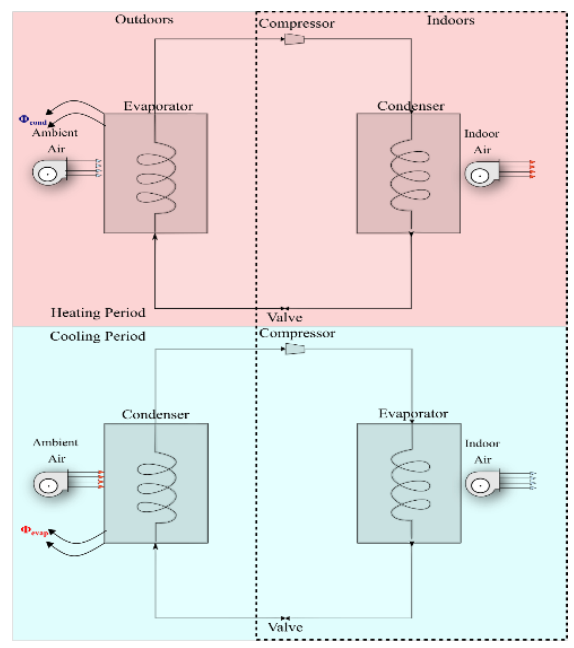

Figure 3: The system fluxes mentioned in the coupling procedure for the cooling and heating period.

The thermal balance of the air volumes $(k)$ in contact with building cells is then reformulated as:

$\rho C_{p} V_{k} \frac{d T_{k}}{d t}=\phi_{c o n v}+\phi_{\text {ventil }}+\phi_{a d v}+\phi_{\text {syst }}$

where the terms of the right part of Equation 2 are the convection, ventilation, advection and systems fluxes respectively.

To achieve this, a low-level networking interface communication has been implemented (socket programming) enabling automatic buffer allocation on send/receive operations. Specifically, the objects of Dimosim are send/received to/from EnviBATE and viceversa for each time step of the simulation through this network communication.

\section{Case study implementation}

Following a mixture geometry between the urban typologies classification of (Stewart and Oke, 2012), and the ones of the Genius Project (Tornay et al. 2017), a discontinuous row of mid-rise high density urban canyon mockup has been developed. The selected urban geometry (Figure 4) enables to discriminate the impact of the urban form on the local climate. In addition, the building complex in the center of the urban block represents a typical urban form for both France and the majority of the European cities. Four different scenarios compose the study (Table 1). Scenarios S1 and S2 correspond to standalone simulations of the tools. S3 is a fully coupled simulation scenario, where both surface temperatures and systems flux were exchanged, while S4 is a coupled simulation scenario in which only the surface temperatures are exchanged.

Table 1: The various standalone and coupled simulation scenarios.

\begin{tabular}{|c|c|c|}
\hline Simulated Scenarios & EnviBATE & Dimosim \\
\hline S1 & $\mathrm{x}$ & \\
\hline S2 & & $\mathrm{x}$ \\
\hline S3 & $\mathrm{x}$ & $\mathrm{x}$ \\
\hline S4 & $\mathrm{x}^{*}$ & $\mathrm{x}^{*}$ \\
\hline
\end{tabular}




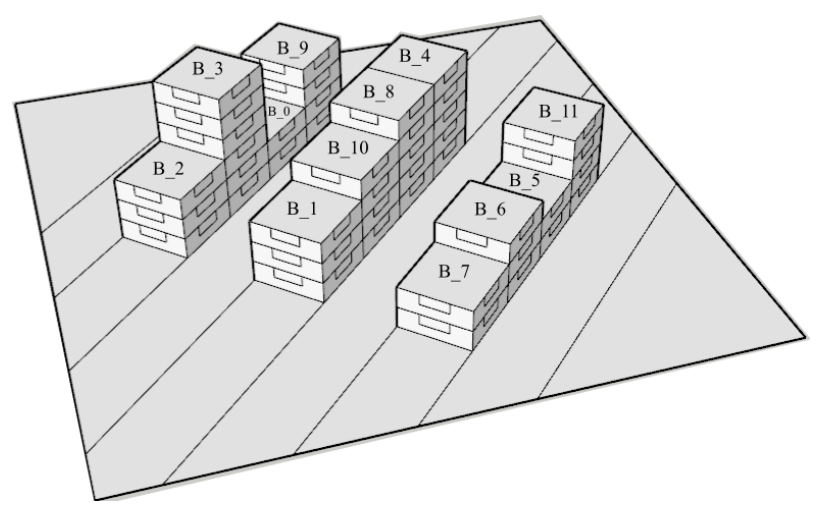

Figure 4: Indexed layout of the studied canyon geometry.

This scenario is tested in order to examine the impact of the microclimate to UBEM without mixing it with the impact of the systems fluxes. The distributed solar radiation is kept identical for all cases in order to eliminate the impact of the different simulation approaches of the tools. The results obtained by the annual simulation of Solene processor have been integrated to both tools as pre-processed data. This option is selected in order to further estimate the uncertainties of solar radiation methods when obstacles (tree shadings) are included or materials of different optical properties for the open spaces are implemented (roads and pavements, cool and conventional, etc.).

\section{EnviBATE initialization}

The district is composed of 16 buildings of various heights randomly selected. The outdoor space is formed by concrete pavements.

Table 2: Summarized characteristics of the simulated canyon district.

\begin{tabular}{|c|c|}
\hline \multicolumn{2}{|c|}{ District Characteristics / Thermal and Optical } \\
Properties
\end{tabular}

The outdoor cells accord the zones distinction in order to ensure that each zone is in contact with an outdoor cell. The spatial resolution of the solar mesh corresponds to maximum $2 \mathrm{~m}$, discretizing each building surface to at least 44 sub-surfaces (triangles), while the airflow calculation has been performed with an hexahedral mesh composed of cubes of $1(\mathrm{dx}) \times 1(\mathrm{dy}) \times 3(\mathrm{dz}) \mathrm{m}$ to reach a final $86 \times 86 \times 36$ grid domain at each axis respectively.
Those various sub models constitute different programming objects and are finally integrated to a unified zonal model.

For the purpose of this first study, vegetation or tree surfaces are not included in order to simplify the mockup as much as possible. Table 2 presents the characteristics of the generated mockup. Concerning the input boundary conditions, the meteorological data correspond to $\mathrm{La}$ Rochelle's typical meteorological year interpolated with CCWorldWeatherGen (M. F. Jentsch et al. 2013) to 2050 according to the A2 future scenario of forcing agents given in the IPCC Special Report. It describes a future world of increasing global population, an economic development which is primarily regionally oriented and the technological change is more fragmented and slower than the other scenarios.

\section{Dimosim initialization}

The building layouts and the respective input data are equally imported to both tools. To serve this scope, a module able to transform the input geometrical files has been developed. Other parameterizations of the model reflect to the systems generation point of view. For the purpose of the present study, we chose to integrate an airconditioning unit on the zone level, as cooling/heating power supplier to each zone. In order to estimate the thermal loads of each zone the implemented sizer object calculates an approximate nominal heating or cooling power for the given thermal zone, as a function of the accumulated U-Value of the zone (sum of U-Values of opaque surfaces and windows multiplied by the respective surface), taking also into account the thermal loses due to ventilation. The fuel used corresponds to electricity and the AC system mode is reversible to account both for cooling and heating seasons.

Subsequently, the generator object estimates the thermal output with respect to the nominal outputs of the sizer.

Table 3: Thermal and optical properties of the buildings composing the district.

\begin{tabular}{|c|c|}
\hline \multicolumn{2}{|c|}{$\begin{array}{c}\text { Building Characteristics / Thermal and Optical } \\
\text { Properties }\end{array}$} \\
\hline Floor Height & $3[\mathrm{~m}]$ \\
\hline Floor Surface & $100\left[\mathrm{~m}^{2}\right]$ \\
\hline Window to wall ratio & 0.2 \\
\hline Roof albedo & 0.3 \\
\hline Roof U-Value & $0.78\left[\mathrm{~W} / \mathrm{m}^{2} \mathrm{~K}\right]$ \\
\hline Wall albedo & 0.3 \\
\hline Wall U-Value & $0.34\left[\mathrm{~W} / \mathrm{m}^{2} \mathrm{~K}\right]$ \\
\hline Floors U-Value & $0.34\left[\mathrm{~W} / \mathrm{m}^{2} \mathrm{~K}\right]$ \\
\hline Window Type & Double glazing \\
\hline Window U-Value & $2.5\left[\mathrm{~W} / \mathrm{m}^{2} \mathrm{~K}\right]$ \\
\hline Window transmissivity & 0.789 \\
\hline Window absorptance & 0.08 \\
\hline Set point cooling / heating & $28 / 19\left[{ }^{\circ} \mathrm{C}\right]$ \\
\hline Infiltration rate & $0.7[\mathrm{ACH}]$ \\
\hline
\end{tabular}

\section{Results}

\section{Standalone Simulation Results}

In this section, the results of the street canyon configuration are analysed for the referenced scenarios 
S1-S4. Concerning the standalone microclimatic simulation S1, EnviBATE seems capable to predict the local UHI effect and its intensity. Figure 5 presents a heat map of annual air temperature difference between the air temperature of the meteorological file and the one obtained in the canopy cells through the simulation. The air temperature difference ranges up to a maximum of 5 ${ }^{\circ} \mathrm{C}$ for the entire period. During the summer period, the average air temperature shows a small increase of approximately $0.4^{\circ} \mathrm{C}$ (Figure 6), while the peak difference occurs at late June, July and August respectively. These extreme temperature values are influenced by the increased air temperature of the meteorological file, combined with local minimum wind speed flow. It is observed mainly at the first layer cells $(0-3 \mathrm{~m})$, as the excessive heat is trapped and overheating phenomena occur in the canyon cells close to the highest buildings of the area. During these time steps, wind speed does not exceed the value of $0.2 \mathrm{~m} / \mathrm{s}$. The amplitude of the absolute maximum difference is $3.2{ }^{\circ} \mathrm{C}, 3.6{ }^{\circ} \mathrm{C}, 1.7{ }^{\circ} \mathrm{C}$ and $3.0^{\circ} \mathrm{C}$ respectively. On the contrary, during the winter period the sensitivity to any temperature increase is low varying from $0.1{ }^{\circ} \mathrm{C}$ to $0.2{ }^{\circ} \mathrm{C}$. Early in the morning or late in the evening, although the specific air temperature of the canyon is similar with that of the meteorological file; the open space cells dominate the trend of the average temperature exhibiting a slight decrease of approximately $0.2^{\circ} \mathrm{C}$.

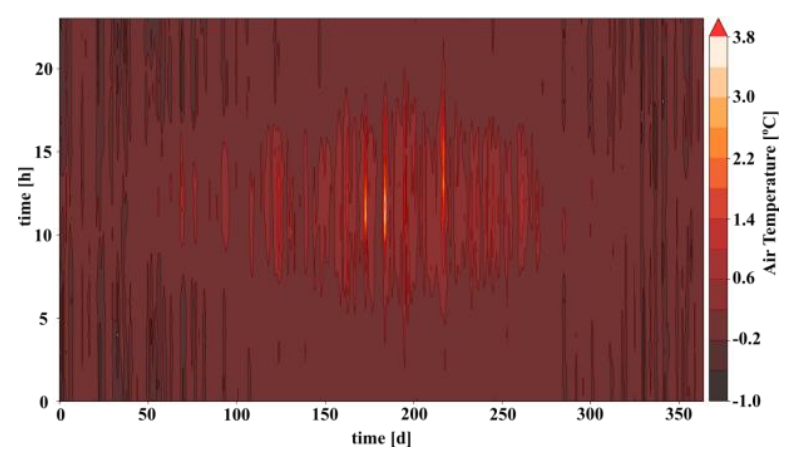

Figure 5: Heat map of the UHI intensity in the studied canyon.

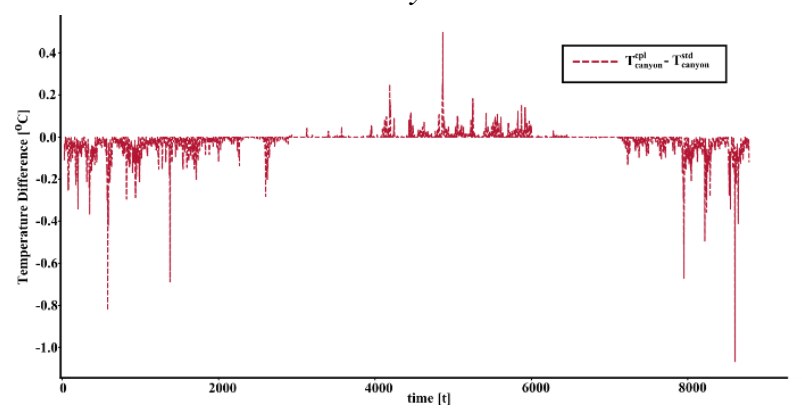

Figure 6: Average air temperature differences inside the canyon between the S3 and S1 simulated scenarios.

\section{Coupling Results}

Concerning the coupled simulation, we emphasize on the comparison of the air temperature and cooling loads between the coupled simulations and the standalone of both tools (S2, S3).
In general, the flux injected to the canopy cells seems to have a significant impact to the ambient temperature of the district (S3). In parallel, the surface temperature obtained by the microclimatic model, influenced by the canyon-increased temperatures leads to an augmentation of the cooling needs of the buildings.

More in detail, the ambient temperatures and the thermal loads of each zone are analysed separately for the cooling and heating period, as their behaviour is different. This might occur due to the building thermal characteristics (indoor insulated to represent the French construction habits) and the climatic zone.

Regarding the ambient temperature, deviations occur during both heating and cooling period. Figure 7 and Figure 9 present a snapshot of the maximum differences respectively. The distribution of the air temperature is also tabulated in the figures.

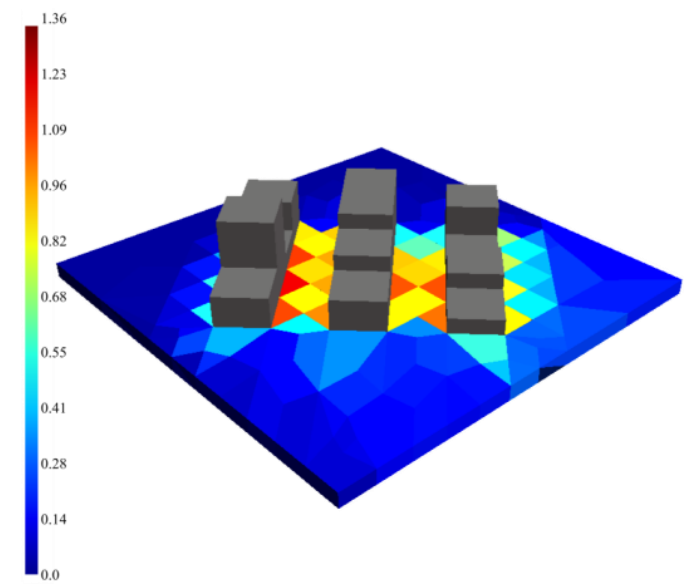

Figure 7: Maximum difference of air temperature distribution in the canyon during the cooling period.

During the summer period, the air temperature of the canyon derived from the coupled simulation is increasing and most of the canyon cells present a $0.2-0.5^{\circ} \mathrm{C}$ increase of air temperature. At the same time the average air temperature of the canyon is slightly higher compared to the standalone simulation (comparison of S3 with $\mathrm{S} 1$ ). The absolute difference varies between $0.1{ }^{\circ} \mathrm{C}$ to $0.4{ }^{\circ} \mathrm{C}$. Albeit the canyon cells are more influenced, as they receive directly the flux of the systems, the ones corresponding to open areas are also affected. This is happening mainly due to the interference of the airflow between the canopy cells, as the tool is capable to estimate these convective exchanges. As expected, the maximum difference occurs at the time steps where the UHI effect is more intense. Moreover, the air cells close to highest buildings are more influenced. As an example, the highest temperature is obtained at the canopy cells, which are in contact with building B_3 (tallest building-canyon oriented). This is in accordance with the higher energy loads in these zones. Since the zones could not reach the respective set point temperature, the cooling demand is increasing and thus the injected flux of the cooling system feeds the canyon cells with excessive heat.

Figure 8 presents the summurized cooling loads per building during the entire cooling season. The data were 
obtained by the comparison of S2 and S3. We can observe that the 2-storey buildings are not affected in the same manner as the 4-storey ones, due either to their position or to the reduced solar radiation received. As an example, the convective exchanges of building B_7, located in the edge of the canyon are higher than the ones at the middle of the canyon. Also the radiative exchanges are different. The building is southwest oriented. The received solar gains are maximized but due to the fact that it is facing the open space the radiative exchanges are also higher (higher view factor / increased multireflexions). On the contrary, building B_4 which is also at the edge of the canyon (but NE oriented), seems to be in the inflection point, as it presents increased cooling needs compared to the standalone simulation. This is mainly triggered by the increased air temperature that occure in the canyon due to the additional fluxes of buildings B_9 and B_11. These two buildings present the highest rate of cooling demand and subsequently the flux injected to the canyon is higher, causing a feedback on air temperatures and cooling loads.

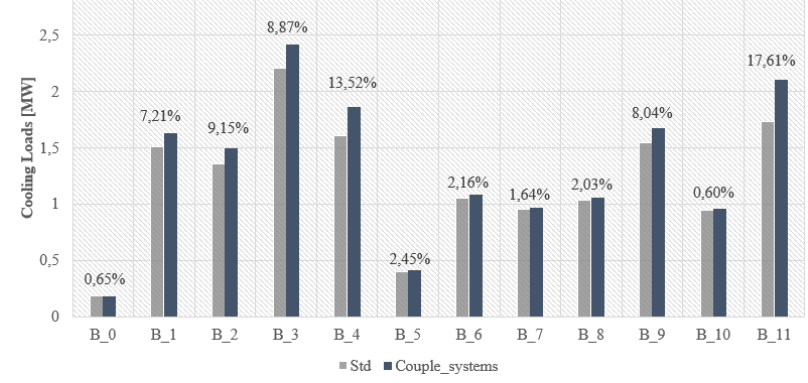

Figure 8: Variations of the cooling loads between $S 2$ and S3 simulated scenarios.

The average increase of the cooling loads is $8.22 \%$, while the peak is reaching almost $18 \%$. The comparison between S3 and S4 shows that the additional flux injected to the canopy does not affect the overall perfomance of the systems but only the peak values. Generally for the entire cooling period the difference between S3 and S4 is almost neglectible reaching maximum the value of $0.02 \%$. Further studies (hourly load differences, different climatic zones, etc.) have to be examined in order to correlate more accurately the temperature increase with the increase of cooling loads. Refering to bilbiography this is in aggreement with (Santamouris, 2015) for a mild climate.

Concerning the heating period, the buildings thermal response is changing. Although the air temperatures are lower (comparison between S1 and S3), the heating loads remain unaffected. More in detail, the energy system is assumed to inject cold air to the canyon and a significant decrease of the air temperature is depicted (Figure 9). The reduction of air temperature occures in the canyon for the coupled simulation (S3). The air temperature of the canopy cells seems to be triggered by the flux injected to them. The main difference is occuring in the second layer cells $(3-6 \mathrm{~m})$, while the respective one for the first layer cells is almost neglectible. The potential increase of the heating demands is not present, although the decreased air temperatures. This could be explained due to the buildings parameterizations. As presented in Table 3, the building stock of the testing district correspond to internal insulated buildings. Thus, for the given ventilation rate the heating set point is achieved and satisfied.

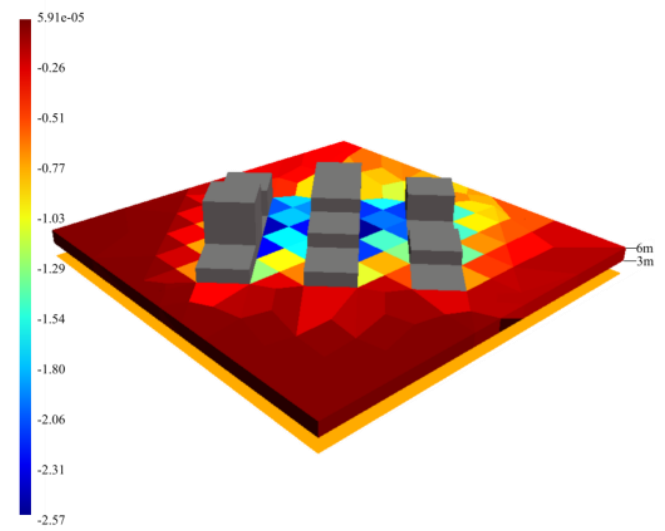

Figure 9: Maximum difference of air temperature distribution in the canyon during the heating period.

\section{Computational Time}

A crucial point in district scale simulations, especially when a microclimatic study is included, is the computational time efficiency. As denoted in the Introduction, such types of efforts are temporally restricted. Usually a representative summer or winter day is selected expressing extreme cases. The information included in an annual hourly time step simulation is lost and generalized. Table provides the computational cost derived from the completion of the simulations with an Intel(R) Xeon (R) CPU E3 -2.80 GHz computer. The stats refer to 9265 number of steps (annual simulation and 20 days of initialization).

Table 4: Computational cost of the simulation tools.

\begin{tabular}{|c|c|}
\hline Simulation Tool & Computational Cost \\
\hline Solene & 59 min (dir+dif) \\
(Solar Radiation Pre-processed) & min (multireflexion) \\
\hline EnviBATE & $\begin{array}{c}5.1 \mathrm{~h}+ \\
\text { (calc. W.factors) }\end{array}$ \\
\hline Dimosim compiled & $2.27 \mathrm{~min}$ \\
\hline $\begin{array}{c}\text { Dimosim } \\
\text { Non-compiled version }\end{array}$ & $31 \mathrm{~min}$ \\
\hline
\end{tabular}

The microclimatic tool, under an extensive performance control check seems to have the potential to reduce the computational time by $30 \%$.

\section{Conclusion}

This work presents a micro co-simulation approach between a microclimatic and an UBES simulation platform. The coupling procedure is based at the simultaneous exchange of buildings surface temperatures and systems injected flux for each time step of the simulation. Based on the results of the study, it is evident that the rise of the canyon temperature varies between 0.1 ${ }^{\circ} \mathrm{C}$ and $0.4{ }^{\circ} \mathrm{C}$, while the maximum air temperature considerably increases to reach locally the $1.36{ }^{\circ} \mathrm{C}$. The potential increase of the cooling demand rise varies between $0.6 \%$ and $17.6 \%$, depending mainly on the location and characteristics of the studied thermal zone. The corresponding penalty of cooling loads of the entire district, increase considerably up to $8.2 \%$. The deviation 
of cooling energy demand signifies that the detailed representation of the outdoor environment is preferred rather than the usage of homogenous boundary conditions.

\section{Future work \& Perspectives}

Although the various sub-models that constitute the presented coupled model are validated in various analytical or comparative tests (eg: BESTest, real case studies) the developed coupled tool has not passed yet an evaluation test. To this aim, an extensive monitoring campaign is ongoing in two districts in the city of La Rochelle, in the framework of the PEDOBUR and EQLORE projects. The monitoring strategy consists of various meteorological stations located inside the districts and around the city for the better understanding of the UHI effect and the respective contribution of the local UHIs to it. In addition, several buildings are monitored with smart meters in terms of air temperature, energy consumption, etc. Moreover, extensive surveys of users behaviour, building characteristics assessment and in-situ observations of the outdoor environment are conducted. The data will be used to tune and validate the coupled model.

Further, in order to better assess the uncertainties of UBEM, an ongoing comparative analysis of highly influenced parameters has been already launched. The coupling methodology presented in this article is going to be performed for several others. Different climate zones, building thermal characteristics and various types of energy systems will be tested to identify the required level of detail on district scale energy simulations.

\section{Coupled model limitations}

The limitations of the coupled model arise from the individual constraints of each tool. Both computational platforms are developed to perform simulations at district scale. The spatial limitation of the microclimatic model is estimated to be $1 \mathrm{~km} \times 1 \mathrm{~km}$, depending on the building characteristics (mainly building height). On the contrary, the UBEM boundaries can be extended close to city scale (thousands of buildings). Moreover, an issue that requires further research arises from the calculation of the surface temperature in the microclimatic model. As explained in Methods section, the calculation requires the solicitation from the indoor air temperature. This parameter is always set to a constant value, representing the indoor set point temperature. This assumption could be neglected in a future possible version of an integrated tool.

\section{References}

Allegrini, J., Orehounig, K., Mavromatidis, G., Ruesch F., Dorer, V. and R. Evins (2015). A Review of Modelling Approaches and Tools for the Simulation of District-Scale Energy Systems. Renewable and Sustainable Energy Reviews 52, 1391-1404.

Bozonnet, E., Musy, M., Calmet, I. and F. Rodriguez (2015). Modeling Methods to Assess Urban Fluxes and Heat Island Mitigation Measures from Street to City Scale. International Journal of Low-Carbon Technologies 10, 62-77.

Bruse, M., and H. Fleer (1998). Simulating SurfacePlant-Air Interactions inside Urban Environments with a Three Dimensional Numerical Model. Environmental Modelling \& Software 13, 373-384.

Eurostat (2017).

Frayssinet, L., Merlier, L., Kuznik, F., Hubert, J-L., Milliez, M. and J-J. Roux (2018). Modeling the Heating and Cooling Energy Demand of Urban Buildings at City Scale. Renewable and Sustainable Energy Reviews 81, 2318-2327.

Gobakis, K. and D. Kolokotsa (2017). Coupling Building Energy Simulation Software with Microclimatic Simulation for the Evaluation of the Impact of Urban Outdoor Conditions on the Energy Consumption and Indoor Environmental Quality. Energy and Buildings 157, 101-115. https://doi.org/10.1016/j.enbuild.2017.02.020.

Grimmond, C. S. B., Blackett, M., Best, M. J., Barlow, J., Baik, J-J., Belcher, S.E. and S. I. Bohnenstengel (2010). The International Urban Energy Balance Models Comparison Project: First Results from Phase 1. Journal of Applied Meteorology and Climatology 49, 1268-92.

Groleau, D., Fragnaud, F. and J.-M. Rosant (2003). Simulation of the Radiative Behavior of an Urban Quarter of Marseille with the Solene Model. Proceedings from ICUC-5: Fifth International Conference on Urban Climate. Lodz (Poland), September 2003.

Gros, A. (2013). Modélisation de La Demande Énergétique Des Bâtiments à l'échelle d'un Quartier. La Rochelle (France).

Gros, A., Bozonnet, E. and C. Inard (2014). Cool Materials Impact at District Scale-Coupling Building Energy and Microclimate Models. Sustainable Cities and Society 13, 254-266.

Jentsch, M. F., James, P. A.B., Bourikas, L. and A. S. Bahaj (2013). Transforming Existing Weather Data for Worldwide Locations to Enable Energy and Building Performance Simulation under Future Climates. Renewable Energy 55, 514524.

Kusaka, H., Kondo, H., Kikegawa, Y. and F. Kimura (2001). A Simple Single-Layer Urban Canopy Model for Atmospheric Models: Comparison with Multi-Layer and Slab Models. BoundaryLayer Meteorology 101, 329-358.

Martilli, A. (2007). Current Research and Future Challenges in Urban Mesoscale Modelling. International Journal of Climatology 27, 19091918.

Martin, M., Wong, N., Hii D. and M. Ignatius (2017). Comparison between Simplified and Detailed EnergyPlus Models Coupled with an Urban Canopy Model. Energy and Buildings 157, 116125. 
Masson, V. (2000). A Physically-Based Scheme For The Urban Energy Budget In Atmospheric Models. Boundary-Layer Meteorology 94, 357-397.

Mauree, D., Coccolo, S., Kaempf, J. and J-L. Scartezzini (2017). Multi-Scale Modelling to Evaluate Building Energy Consumption at the Neighbourhood Scale. PLOS ONE 12, 1-21.

Munck, C., Pigeon, G., Masson, V., Meunier, F., Bousquet, P., Tréméac, B., Merchat, M., Poeuf, P. and C. Marchadier (2013). How Much Can Air Conditioning Increase Air Temperatures for a City like Paris, France?. International Journal of Climatology 33, 210-227.

Pardyjak, E. and M. Brown (2003). QUIC-URB v1.1 Theory and User's Guide. California (US)

Perera, A.T.D., Coccolo, S., Scartezzini, J-L, and D. Mauree (2018). Quantifying the Impact of Urban Climate by Extending the Boundaries of Urban Energy System Modeling. Applied Energy 222, 847-860.

Riederer, P., Partenay, V., Perez, N., Nocito, C., Trigance, R. and T. Guiot (2015). Development of a Simulation Platform for the Evaluation of District Energy System Performances.
Proceedings from BS2015: Building Simulation Conference. Hyderabad (India), 7-9 December 2015.

Rousseau, S. (1978). Simulation numérique du comportement thermique des locaux d'habitation: évaluation de l'influence de la radiation solaire, des conditions climatiques et des paramètres caractéristiques du bâtiment. Lyon (France).

Santamouris, M., Cartalis, C., Synnefa, A. and D. Kolokotsa (2015). On the Impact of Urban Heat Island and Global Warming on the Power Demand and Electricity Consumption of Buildings-A Review. Energy and Buildings 98, 119-124.

Stewart, I.D., and T.R. Oke (2012). Local Climate Zones for Urban Temperature Studies. American Meteorological Society 93, 1879-1900.

Tornay, N., Schoetter, R., Bonhomme, M., Faraut, S. and V. Masson (2017). GENIUS: A Methodology to Define a Detailed Description of Buildings for Urban Climate and Building Energy Consumption Simulations. Urban Climate 20, 75-93. 